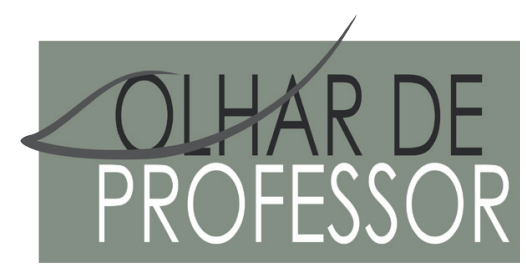

DOI: 10.5212/OLHARPROFR.v23.2020.15041.209209223758.0326

\title{
O PAPEL DA MOBILIDADE INTERNACIONAL NA FORMAÇ̃̃O DOCENTE: ESTUDO COMPARADO ENTRE BRASIL E PORTUGAL
}

\author{
THE ROLE OF INTERNATIONAL MOBILITY IN TEACHER EDUCATION: A COMPARATED STUDY BETWEEN \\ BRAZIL AND PORTUGAL \\ EL PAPEL DE LA MOVILIDAD INTERNACIONAL EN LA FORMACIÓN DEL PROFESORADO: UN ESTUDIO \\ COMPARATIVO ENTRE BRASIL Y PORTUGAL
}

\author{
VLADEMIR MARIM* \\ LETíCIA ARAÚJO RODRIGUES ${ }^{* *}$
}

\begin{abstract}
Resumo: O objetivo geral deste trabalho consiste em analisar as convergências e divergências entre as mobilidades internacionais do Programa de Licenciaturas Internacionais (PLI), do Programa Ibero-Americanas e do Programa Erasmus, presentes na formação docente e que são desenvolvidas em Portugal. Como metodologia de pesquisa utilizamos a metodologia comparada, composta das fases: Descritiva, Interpretativa, Justaposição e Comparativa. A partir da análise dos dados percebemos a importância das políticas públicas de incentivo à formação docente, posto que estas auxiliam as instituições responsáveis pela qualificação destes profissionais a oferecerem uma formação inicial mais qualificada e que atenda novas demandas educativas da sociedade contemporânea.
\end{abstract}

Palavras-chave: Aprendizagem Discente. Formação Inicial. Intercâmbio.

Abstract: This work is the result of an investigation whose general objective is to analyze how convergences and divergences between the international mobilities of the International Licensing Program (ILP), the IberoAmerican Program and the Erasmus Program, present in teacher training and which are carried out in Portugal. As the research methodology used the comparated methodology, composed of the phases: Descriptive, Interpretive, Juxtaposition and Comparative. From the analysis of the perceived data, the importance of public policies to encourage teacher training, since these auxiliaries are applied by specialized higher education institutions, offers more qualified initial training and new educational activities in contemporary society.

Keywords: Student Learning. Teacher Education. International Mobility.

Resumen: Esta investigación tiene como objetivo general el analizar las convergencias y divergencias entre las movilidades internacionales del Programa de Licenciatura Internacional (PLI), el Programa Iberoamericano y el Programa Erasmus, presente en la formación del profesorado y que se desarrollan en Portugal. Como metodología de investigación utilizamos la metodología comparativa, compuesta de las fases: descriptiva, interpretativa, yuxtaposición y comparativa. A partir del análisis de los datos, nos dimos cuenta de la importancia de las políticas públicas para alentar la formación del profesorado, ya que ayudan a las instituciones responsables de la calificación de estos profesionales a ofrecer una formación inicial de más calidad y que satisfaga las nuevas demandas educativas de la sociedad contemporánea.

Palabras clave: Aprendizaje del Estudiante. Formación de Docentes. Movilidad Internacional.

\footnotetext{
* Doutor e Mestre em Educação pela Pontifícia Universidade Católica de São Paulo (PUC.SP). Professor do Programa de Pós-Graduação em Ensino de Ciências e Matemática (PPGECM) da Universidade Federal de Uberlândia (UFU). E-mail: marim@ ufu.br

${ }^{* *}$ Graduada em Matemática pela Faculdade de Matemática (FAMAT) da Universidade Federal de Uberlândia. E-mail: leticiaucufu@gmail.com
} 


\section{INTRODUÇ̃̃̃O}

Segundo os dados estatísticos apresentados pela Organização para Cooperação e Desenvolvimento Econômico (OCDE) sobre o Programa Internacional de Avaliação de Estudantes (PISA), realizado no ano de 2018, é incontestável que a educação brasileira precisa de mudanças, em razão do baixo desempenho dos estudantes brasileiros nas áreas de Leitura, Matemática e Ciências avaliadas pelo PISA.

Reconhecemos a necessidade de se estabelecer ações na educação que contribuam para a mudança desse cenário. Logo, para que haja mudança é preciso investir na Educação Básica de forma ampla, inclusive na formação docente. Conscientes da importância do incentivo à formação docente, o problema desta investigação é: Quais são as convergências e as divergências entre as mobilidades internacionais do Programa de Licenciaturas Internacionais (PLI), do Programa Ibero-Americanas e do Programa Erasmus, presentes na formação docente e que são desenvolvidas em Portugal?

Para respondermos a essa problematização, elencamos como objetivo geral desta pesquisa em analisar as convergências e divergências entre as mobilidades internacionais do Programa de Licenciaturas Internacionais, do Programa Ibero-Americanas e do Programa Erasmus, presentes na formação docente desenvolvidas em Portugal com participação de alunos brasileiros.

Para desenvolvermos o objetivo geral traçamos os seguintes objetivos específicos: (a) conhecer as propostas dos programas de mobilidades, Programa de Licenciaturas Internacionais, Programa IberoAmericanas e Programa Erasmus presentes na formação docente no Brasil e Portugal; (b) comparar as propostas identificadas nos programas de mobilidades supramencionados; (c) compreender os saberes docentes e as competências necessárias para a formação docente de Matemática para atuar na Educação Básica brasileira; e (d) identificar e compreender quais são as contribuições que os programas de mobilidades desenvolvidos na formação docente podem tornar o estudante um profissional melhor qualificado para o mercado de trabalho.

Como metodologia de pesquisa faremos uso da Metodologia Comparada, que nos permitirá aferir as contribuições da mobilidade internacional na formação docente. Para identificarmos estas contribuições, descreveremos, baseados em documentos oficiais, os três programas de mobilidade internacional citados anteriormente e levaremos em consideração o contexto sociopolítico dos dois países, Brasil e Portugal.

Assim sendo, o desenvolvimento da pesquisa dar-se-á em quatro partes. A primeira parte trará dados gerais dos países Brasil e Portugal. A segunda parte abordará a metodologia de educação comparada. Já na terceira parte buscaremos compreender os saberes docentes e as competências necessárias para a formação docente de Matemática para atuar na Educação Básica brasileira. Para concluir, na quarta e última parte faremos a justaposição e comparação das propostas identificadas nos programas de mobilidade, seguida das considerações e referências utilizadas no estudo desta pesquisa

\section{METODOLOGIA COMPARADA}

A Comparatista Bereday (1968), propõem algumas etapas necessárias para que um estudo seja reconhecido como comparativo. Estas etapas ou fases são designadas: (a) descritiva; (b) interpretativa; (c) justaposição; e (d) comparativa.

A primeira fase do Método Comparativo é a fase descritiva. Esta fase é o momento em que nos dedicamos a explorar o objeto de estudo de forma a obter um conhecimento amplo e significativo do mesmo. Assim sendo, nesta fase selecionamos fontes confiáveis de pesquisas, coletamos dados e assim descrevemos minuciosamente o nosso objeto de estudo.

A segunda fase do Método é a fase interpretativa. Segundo Raventós (1983, p. 69), tem por objetivo "por um lado, detectar e eliminar erros de dados e informações coletados previamente e por outro lado, analisar e interpretar adequadamente e de forma pormenorizada estes mesmos dados e informações”.

Desta maneira, para que tenhamos condições de analisar e interpretar de forma pormenorizada os dados coletados, é importante a busca de diferentes abordagens e a contextualização dos dados levando em consideração, para a nossa análise, os diversos elementos que influenciam o objeto de estudo, tais como: elementos culturais, econômicos, sociais e políticos. 
A fase de justaposição é a terceira fase do Método Comparativo e é ela que nos permite estabelecer de forma objetiva as convergências e divergências do objeto estudado.

Caballero et al. (2016) nos dizem que é uma fase chave, que constitui a fase comparativa real, conseguida graças aos dados recolhidos nas fases anteriores. Nesta fase se apresentam os dados já descritos e analisados, dois a dois, em paralelo, de modo que colocamos em relação ao que queremos comparar.

Nesta fase consideramos apenas os dados coletados dos elementos de comparação e colocamos estes dados em paralelo, permitindo-nos extrair dos mesmos suas convergências e divergências. Tais informações podem ser representadas fazendo uso, por exemplo, de quadros esquemáticos, gráficos de barras, setores, linhas e de eixos.

Caballero et al. (2016) ressaltam que a ordem dos elementos de comparação é estabelecida de modo que os elementos de um sistema que correspondem aos mesmos de outro(s) sistema(s) são justapostos, sendo que o número de elementos pode variar dependendo do estudo que está sendo realizado.

A última fase desse método é a fase comparativa. Nela fazemos uma leitura e comentários críticos dos gráficos apresentados na fase de justaposição, o que nos permitirá obter conclusões do nosso objeto de estudo, gerando novos conhecimentos decorrentes da comparação (VELLOSO; PEDRÓ, 1991, apud CABALERRO at al., 2016).

É sem dúvida neste último estágio da análise comparativa onde maiores rendimentos podem ser obtidos a comparação, e onde o exercício do método comparativo nos demonstra suas possibilidades de aplicação e a capacidade que pode e deve ter o desenvolvimento incorporado na atualidade, em todas ou quase todas as universidades do mundo: a Educação Comparada (RAVENTÓS, 1983, p. 71).

Segundo Cabalerro et al. (2016), para realizar uma boa análise dos dados expostos na fase anterior, devemos seguir tais procedimentos: (a) comece a avaliação dos resultados do geral e progressivamente ir para o particular; (b) consulte primeiro os valores máximos, depois os valores mínimos e finalmente os valores médios; (c) comente detalhadamente as convergências (os dados que estão próximos da média, as semelhanças e os valores mais repetidos), divergências (particularidades, os valores mais afastados da média ou os valores menos frequentes) e tendências (são dados emergentes que nos permitem fazer suposições sobre o futuro). Isso nos permite fazer uma justificativa interpretativa global; e (d) faça uma subseção sobre os casos chamativos, explique-os e avalie-os.

A árvore de categorias, parâmetros e indicadores de comparação que apresentaremos no Quadro 1, a seguir, nos auxiliará na sistematização de informações e posteriormente na justaposição e comparação de elementos.

QUADRO 1 - ÁRVORE DE CATEGORIAS, PARÂMETROS E INDICADORES

\begin{tabular}{|c|c|c|}
\hline CATEGORIAS & PARÂMETROS & INDICADORES \\
\hline \multirow{9}{*}{$\begin{array}{c}1 \text { Contexto Sociopolítico do } \\
\text { Brasil e de Portugal }\end{array}$} & \multirow{9}{*}{ 1.1 Cenário Sociopolítico } & 1.1.1 Localização \\
\hline & & 1.1.2 Tamanho da População \\
\hline & & 1.1.3 Extensão Territorial \\
\hline & & 1.1.4 Distribuição Territorial \\
\hline & & 1.1.5 Sistema Político \\
\hline & & 1.1.6 Idioma oficial \\
\hline & & 1.1.7 Moeda oficial \\
\hline & & 1.1.8 Bloco Econômico \\
\hline & & 1.1.9 Aspectos constitucionais \\
\hline \multirow{5}{*}{2 Instituições Formadoras } & \multirow{5}{*}{$\begin{array}{l}\text { 2.1 Contexto Histórico, } \\
\text { Geográfico e Acadêmico }\end{array}$} & 2.1.1 História \\
\hline & & 2.1.2 Localização \\
\hline & & 2.1.3 Fundação \\
\hline & & 2.1.4 Ingresso \\
\hline & & 2.1.5 Cursos de graduação \\
\hline
\end{tabular}


conclusão

\begin{tabular}{|c|c|c|}
\hline CATEGORIAS & PARÂMETROS & INDICADORES \\
\hline \multirow{6}{*}{2 Instituições Formadoras } & \multirow{6}{*}{ 2.2 Curso de Matemática } & 2.2.1 Criação do curso \\
\hline & & 2.2.2 Duração do curso \\
\hline & & 2.2.3 Carga horária $(\mathrm{CH})$ \\
\hline & & 2.2.4 Distribuição das disciplinas \\
\hline & & 2.2.5 Aproveitamento das disciplinas \\
\hline & & 2.2.6 Titulação/habilitação \\
\hline \multirow{30}{*}{3 Programas de Mobilidade } & \multirow{10}{*}{$\begin{array}{l}\text { 3.1 Programa de } \\
\text { Licenciaturas Internacionais }\end{array}$} & 3.1.1 História \\
\hline & & 3.1.2 Objetivo \\
\hline & & 3.1.3 Duração da mobilidade \\
\hline & & 3.1.4 Requisitos de participação \\
\hline & & 3.1.5 Países de destino \\
\hline & & 3.1.6 Áreas de estudos \\
\hline & & 3.1.7 Regime de estudos \\
\hline & & 3.1.8 Equivalência de disciplinas \\
\hline & & 3.1.9 Benefícios/Recursos \\
\hline & & 3.1.10 Produto Final \\
\hline & \multirow{10}{*}{$\begin{array}{l}3.2 \text { Programa } \\
\text { Ibero-Americanas }\end{array}$} & 3.2.1 História \\
\hline & & 3.2.2 Objetivo \\
\hline & & 3.2.3 Duração da mobilidade \\
\hline & & 3.2.4 Requisitos de participação \\
\hline & & 3.2.5 Países de destino \\
\hline & & 3.2.6 Áreas de estudos \\
\hline & & 3.2.7 Regime de estudos \\
\hline & & 3.2.8 Equivalência de disciplinas \\
\hline & & 3.2.9 Benefícios/Recursos \\
\hline & & 3.2.10 Produto Final \\
\hline & \multirow{10}{*}{ 3.3 Erasmus } & 3.3.1 História \\
\hline & & 3.3.2 Objetivo \\
\hline & & 3.3.3 Duração da mobilidade \\
\hline & & 3.3.4 Requisitos de participação \\
\hline & & 3.3.5 Países de destino \\
\hline & & 3.3.6 Áreas de estudos \\
\hline & & 3.3.7 Regime de estudos \\
\hline & & 3.3.8 Equivalência de disciplinas \\
\hline & & 3.3.9 Benefícios/Recursos \\
\hline & & 3.3.10 Produto Final \\
\hline
\end{tabular}

FONTE: QUADRO ELABORADO PELOS AUTORES (2019).

A árvore apresenta, de forma esquemática, as categorias abordadas na pesquisa, que se dividem no contexto sociopolítico do Brasil e de Portugal; nas instituições formadoras e nos programas de mobilidade. Tais categorias apresentam parâmetros e indicadores específicos de acordo com o tema abordado. Para futura justaposição e análise das categorias elencadas no quadro 1, os dados foram coletados a partir de documentos oficiais disponibilizados de forma virtual pelos governos brasileiro e português, incluindo as Diretrizes e Bases que regem o sistema educacional desses dois países. 


\section{FORMACSÃO NAS EXPERTISES DOCENTE: SABERES NECESSÁRIOS}

Ao enfatizar a profissão docente na contemporaneidade, refletiremos sobre a importância do processo de profissionalização para atender as expectativas do mundo globalizado, as competências e saberes exigidos deste profissional, também as necessidades e desafios da carreira docente.

As constantes transformações sociais e o avanço tecnológico, devido à globalização, exigem o repensar no processo de ensino e aprendizagem. O professor que trabalha com metodologias baseadas no sistema de ensino do século passado, já não atende as competências e habilidades exigidas no novo cenário educacional.

Os alunos do século XXI pertencem à era digital, em que novas informações lhes chegam instantaneamente. Assim sendo, despertar o interesse, contextualizar o ensino e prender a atenção desses alunos tem se tornado uma missão cada vez mais complexa e, portanto, o antigo modelo de ensino, pautado apenas na memorização e repetição, não é eficaz para os estudantes da atualidade.

De acordo com documentos oficiais, tais como a Base Nacional Comum Curricular, o componente curricular de Matemática do Ensino Fundamental deve garantir aos alunos o desenvolvimento de algumas competências específicas, dentre elas: "Desenvolver o raciocínio lógico, o espírito de investigação e a capacidade de produzir argumentos convincentes, recorrendo aos conhecimentos matemáticos para compreender e atuar no mundo” (BRASIL, 2018, p. 267).

Para que os alunos possam desenvolver estas competências, precisamos, então, formar docentes para trabalhar neste cenário educacional atual, ou seja, docentes criativos, dinâmicos, contextualizadores e inovadores, que sejam capazes de atuar e atender as expectativas do mundo globalizado. Nessa perspectiva, buscamos repensar a prática docente e compreender as competências e saberes necessários para a formação docente, sendo mais um desafio para o professor contemporâneo.

Reconhecendo a importância do desenvolvimento de competências e saberes docentes, Ghedin (2009) propõe temáticas a serem exploradas na formação de professores, tais como: saber docente, reflexão sobre a prática e competências da formação, as quais discutiremos a seguir.

O saber docente diz respeito a uma série de conteúdos que o professor precisa dominar para que ele possa atuar na área de ensino. Desta forma, o autor defende que a profissão docente não se trata de vocação, apesar de que, algumas pessoas pareçam ter certo “dom” para ensinar. No entanto, o que torna o professor um profissional do ensino é "um processo formativo, adequado, pensado intencionalmente de uma determinada forma e ação que permite intervir politicamente na organização da sociedade, considerando os limites históricos sociais e políticos, também da nossa própria atuação” (GHEDIN, 2009, p. 6).

Desta forma, não é qualquer pessoa que pode atuar como professor, pois a qualificação do mesmo depende de uma formação estruturada que o condicione a esta prática e, logo, o processo formativo não pode ser ignorado.

No livro intitulado "Saberes docentes e formação profissional”, Tardif (2002) aborda os diferentes saberes que integram a prática docente, os quais influenciam a atuação do professor em sala de aula. De acordo com o autor, o saber docente é um saber plural, proveniente da formação profissional e de saberes disciplinares, curriculares e experiências.

Os saberes decorrentes da formação profissional são aqueles difundidos pelas instituições de formação inicial e contínua de professores. Por meio desta, os docentes adquirem saberes das ciências da educação e pedagógicos.

Já os saberes disciplinares são aqueles adquiridos através das disciplinas oferecidas pelos cursos e departamentos universitários, ou seja, se derivam das disciplinas específicas de cada curso, por exemplo, cálculo numérico, análise funcional, estruturas algébricas e outras.

Quanto aos saberes curriculares, podemos compreendê-los como saberes obtidos pela aplicação dos programas escolares e, os saberes experiências, aqueles desenvolvidos diariamente por meio da prática docente e do conhecimento de seu meio.

Nessa perspectiva, Tardif (2002) define o professor ideal como "alguém que deve conhecer sua matéria, sua disciplina e seu programa, além de possuir certos conhecimentos relativos às ciências da 
educação e à pedagogia e desenvolver um saber prático baseado em sua experiência cotidiana com os alunos” (TARDIF, 2002, p. 39).

Outro ponto a ser explorado na formação de professores é a reflexão sobre a prática. Esta se traduz na capacidade de questionar, de problematizar determinada situação e, portanto, não deve ser apenas uma tendência voltada à formação docente. A reflexão de nossas ações clareia nossos pensamentos e, consequentemente, orienta nosso modo de agir e significa o que fazemos.

De acordo com Freire (2002), a reflexão crítica sobre a prática é essencial na formação permanente dos professores. Nessa perspectiva, destacamos a importância da troca de experiências destes profissionais, através, por exemplo, de encontros que visam a partilha de saberes, pesquisas, atividades implementadas nas escolas ou relatos de experiências.

O professor reflexivo identifica, por exemplo, pontos que poderiam ter sido mais explorados, informações que ficaram desconexas, novas formas de abordar determinado conteúdo, dentre outros. Assim sendo, a atitude reflexiva do docente deve ser contínua para que o ensino seja efetivo.

Por fim, no intuito de identificarmos as competências necessárias à prática docente, buscamos, a seguir, conceituar o termo competência. De acordo com Cardoso e Hora (2013, p. 4), “[...] competência é a capacidade de usar nossas inteligências, nossos pensamentos, memória e outros recursos mentais para realizar com eficiência uma tarefa desejada. Competência é a operacionalização da inteligência, e a forma concreta e prática de colocá-la em ação".

Dessa maneira, de acordo com o MEC, o conceito de competência apoia-se no domínio de saberes teóricos, mas também, de saberes advindos da prática, isto é, derivados da atuação profissional. Marcelo (2013), apud Marim e Manso (2018, p. 44), lista sete competências essenciais ao professor da contemporaneidade:

(a) desenvolver a integridade intelectual; (b) utilizar e avaliar o desenvolvimento de juízos; (c) desenvolver habilidades visuais, linguística, estética e imaginativa como base para o diálogo e para o discurso intra e intercultural; (d) desenvolver a capacidade de análise da política global e habilidades como a comunicação, a resolução de problemas e de conflitos; (e) ampliar as competências básicas de aprendizagem e desenvolvimento; (f) melhorar o desenvolvimento dos valores e atitudes e suas aplicações como critério para tomar decisões equilibradas e sensíveis; (g) possuir reflexividade crítica; (h) desenvolver habilidades de tomada de decisões colaborativas e participativas baseadas em juízos racionais; e (i) facilitar a compreensão da história do seu próprio país em todo o seu contexto histórico e o desenvolvimento mundial.

Para o desenvolvimento das competências docentes destacadas pelo autor é necessária uma formação inicial diferenciada e incentivo a processos de aprimoramento profissional, tais como a formação continuada, que permite aos professores acompanharem as novas tendências educacionais. Ao abordar a figura do professor, Marim e Manso (2018, p. 43) caracterizam o docente competente como:

Um educador comprometido com a construção de uma sociedade justa e democrática, em que o conhecimento e poder são elementos de interferência e organização das relações da solidariedade e não de dominação entre as pessoas. O professor necessita, além do conhecimento específico dos conteúdos que ensina, possuir competências de avaliação, resolução de conflitos, análise de textos, entre muitas outras.

Assim sendo, o professor competente é aquele que compreende que a escola tem a função social de formar pessoas hábeis que "saibam fazer", isto é, pessoas capazes de se planejarem e resolverem problemas, e, portanto, compreende que ele, como docente, é essencial para a efetivação dessa função social.

Por meio dos conceitos de competência partilhados por diferentes autores e de acordo com as competências essenciais ao docente, percebemos que a sociedade atual precisa de docentes criativos, dinâmicos, contextualizadores e inovadores e a formação inicial e continuada são peças-chave para a construção destes professores. 


\section{DESAFIOS DE SER PROFESSOR NA CONTEMPORANEIDADE}

Ensinar não é uma tarefa simples e exercida naturalmente, pois envolve o relacionamento de seres humanos e estes se apresentam na sala de aula com diversos problemas e aflições que, sem dúvidas, influenciam o aprendizado. Desta forma, Nóvoa (2002) nos traz argumentos que reforçam a complexidade de ensinar: (i) dependência da colaboração do aluno/aprendiz; e (ii) emoções.

O autor enfatiza a complexidade do ensino, devido à dependência da colaboração do aluno, dizendo que "ninguém ensina a quem não quer aprender" (NÓVOA, 2002, p. 23). De fato, da nossa vivência em sala de aula constatamos que o sucesso do trabalho docente é influenciado pela cooperação e interesse dos discentes e, como sabemos, frequentemente, o aluno presente na sala de aula não está na escola por uma escolha pessoal, o que o faz não colaborar e comprometer o ensino.

Além da dependência da colaboração do aprendiz, o professor precisa lidar com suas próprias emoções e as dos discentes. Seria insensato acreditar que o aluno ao entrar na escola se desliga de seus problemas, sentimentos e aflições e, portanto, o professor não é formado apenas para trabalhar com os saberes científicos, pois ele também precisa lidar com problemas emocionais para ter sucesso em ensinar e, logo, o professor precisa ser formado para ter uma relação social com toda a comunidade escolar.

Desse modo, constatamos que ser professor perpassa diversos desafios, uma vez que, o ensino envolve seres humanos e, logo, situações imprevisíveis que deverão ser trabalhadas para a promoção do ensino de qualidade e efetivo.

Além do que já foi exposto, diversos estudos apontam o aumento do número de professores que abandonam a profissão e isso se deve a diversos fatores. Um dos motivos é a desvalorização da profissão docente. Marim e Manso (2018) destacam que a valorização do professor pode ser alcançada por meio de uma política integral de educação, que leve em consideração: a formação inicial, as condições de trabalho e salários, o plano de carreira, a formação contínua, entre outros.

Reconhecida a importância da formação continuada dos professores, outro desafio é a busca pela mesma, uma vez que não são dadas as condições necessárias para que os docentes busquem por tal formação. Contudo, para que esse direito seja assegurado, os professores precisam ter outros direitos assegurados, tais como: carga horária, inclusa na jornada de trabalho, para estudos; acesso a cursos de formação; acesso a bibliografias, dentre outros.

Diante da necessidade de uma boa formação inicial e continuada, surgem alguns questionamentos: As instituições responsáveis pela formação inicial e continuada dos professores estão preparadas para formar o docente que a sociedade moderna precisa? As instituições formadoras possuem o incentivo/ apoio governamental necessário para oferecerem a "formação docente ideal”?

Diante destes questionamentos, percebemos que as políticas públicas de desenvolvimento docente podem auxiliar as instituições responsáveis pela qualificação destes profissionais a oferecerem uma formação inicial e continuada de melhor qualidade e que atendem as novas demandas educativas da sociedade contemporânea.

\section{JUSTAPOSIÇÃO E COMPARAÇÃO}

A metodologia comparada abrange quatro fases: descritiva, interpretativa, justaposição e comparação. Nela construímos a árvore de categorias, parâmetros e indicadores do objeto de estudo, para que possamos erigir a análise dos dados selecionados para esta investigação.

\section{CENÁRIOS DOS PAÍSES: BRASIL E PORTUGAL}

Observando o Quadro 1, segundo dados do IBGE (2020) e da União Europeia (2019), percebemos diferenças geográficas entre os dois países. Notemos que o Brasil está localizado na América do Sul e Portugal no sudoeste da Europa. Além disso, o Brasil pertence ao bloco econômico Mercado Comum 
do Sul (MERCOSUL) e é administrado por um sistema Presidencial de República Federal, ao passo que, Portugal é país-membro da União Europeia (UE) e constitui-se como uma República Democrática Semipresidencialista.

QUADRO 2 - CENÁRIO SOCIOPOLIITICO DE BRASLL E PORTUGAL

\begin{tabular}{|c|c|c|}
\hline & Brasil & Portugal \\
\hline Localização & América do Sul & Sudoeste da Europa \\
\hline Bloco econômico & MERCOSUL & União Europeia (UE) \\
\hline Sistema Político & Presidencial de República Federal & $\begin{array}{c}\text { República Democrática } \\
\text { Semipresidencialista }\end{array}$ \\
\hline População & $210.147 .125(2019)$ & $10.276 .617(2018)$ \\
\hline População por gênero & 102.760 .295 homens & 4.852 .366 homens \\
\hline Extensão Territorial & 107.386 .830 mulheres & 5.424 .251 mulheres \\
\hline Distribuição territorial & 26 Estados e 1 Distrito Federal & 18 distritos e duas regiões autônomas \\
\hline Idioma Oficial & Português & Português \\
\hline Moeda & Real & Euro \\
\hline
\end{tabular}

FONTE: QUADRO ELABORADO PELOS AUTORES (2019).

Relativamente à distribuição territorial dos dois países, o Brasil está dividido em 26 estados e 1 Distrito Federal, enquanto Portugal está dividido em 18 distritos e duas regiões autônomas. Podemos dizer que os dois países estão igualmente divididos, uma vez que tanto os Estados e o Distrito Federal do Brasil quanto os Distritos e as regiões autônomas de Portugal possuem autonomias político econômica, mas que precisam respeitar a Constituição do país e a administração central. Outro ponto comum entre os dois países é que ambos possuem a língua portuguesa como idioma oficial.

Quanto à população e extensão territorial dos países, percebemos que a população brasileira é aproximadamente 20 vezes maior que a população portuguesa e que se acomoda em torno de 92 países com a mesma área de Portugal em seu território.

Explorando a quantidade de pessoas por $\mathrm{km}^{2}$ em cada país temos, no Brasil, em torno de, 24,69 habitantes por $\mathrm{km}^{2}$ e em Portugal, cerca de 111,52 habitantes por km². Além disso, tanto no Brasil quanto em Portugal a população feminina supera a masculina, sendo que, as mulheres representam, respectivamente, $51,10 \%$ e 52,78\% da população desses países.

No Brasil, desde 1994 a moeda oficial é o Real e, em Portugal, desde 1999, quando o país tornou-se parte da zona euro, a moeda oficial é o Euro.

Neste cenário apresentado, a comparação entre os dois países, no viés sociopolítico e econômico, evidencia as semelhanças e diferenças entre eles, que segundo Marim e Manso (2018), são necessários conhecê-los para que os gestores educacionais possam conduzir políticas públicas de formação docente diante de sua realidade.

Por meio do Quadro 3, observamos que as constituições que regem Brasil e Portugal, de acordo com Belchior (2013), apresentam aspectos educacionais convergentes. 


\begin{tabular}{|c|c|c|}
\hline & Constituição que rege o Brasil - 1988 & Constituição que rege Portugal - 1976 \\
\hline \multirow{3}{*}{$\begin{array}{c}\text { Principais } \\
\text { aspectos } \\
\text { educacionais }\end{array}$} & $\begin{array}{c}\text { Art. 205. A educação, direito de todos e dever } \\
\text { do Estado e da família, será promovida e } \\
\text { incentivada com a colaboração da sociedade, } \\
\text { visando ao pleno desenvolvimento da pessoa, } \\
\text { seu preparo para o exercício da cidadania e sua } \\
\text { qualificação para o trabalho; } \\
\text { Art. 206. O ensino será ministrado com base } \\
\text { nos seguintes princípios: } \\
\text { Igualdade de condições para o acesso e } \\
\text { permanência na escola; }\end{array}$ & $\begin{array}{c}\text { ARTIGO } 74 .^{\circ} \text { (Ensino) } \\
\text { Todos têm direito ao ensino com garantia do } \\
\text { direito à igualdade de oportunidades de acesso } \\
\text { e êxito escolar. }\end{array}$ \\
\hline & $\begin{array}{c}\text { Art. 208. O dever do Estado com a educação } \\
\text { será efetivado mediante a garantia de: } \\
\text { Educação básica obrigatória e gratuita dos } 4 \\
\text { aos } 17 \text { anos de idade, assegurada inclusive } \\
\text { sua oferta gratuita para todos os que a ela não } \\
\text { tiveram acesso na idade própria; } \\
\text { Progressiva universalização do ensino médio } \\
\text { gratuito; }\end{array}$ & $\begin{array}{c}\text { ARTIGO 74. } \text {. (Ensino) }^{\text {AR }} \\
\text { Na realização da política de ensino incumbe } \\
\text { ao Estado: } \\
\text { Assegurar o ensino básico universal, } \\
\text { obrigatório e gratuito; } \\
\text { Estabelecer progressivamente a gratuidade de } \\
\text { todos os graus de ensino; }\end{array}$ \\
\hline & $\begin{array}{c}\text { Art. 207. As universidades gozam de } \\
\text { autonomia didático-científica, administrativa } \\
\text { e de gestão financeira e patrimonial, e } \\
\text { obedecerão ao princípio de indissociabilidade } \\
\text { entre ensino, pesquisa e extensão. }\end{array}$ & $\begin{array}{l}\text { ARTIGO } 76 .^{\circ} \text { (Universidade e acesso ao } \\
\text { ensino superior) } \\
\text { As universidades gozam, nos termos da lei, de } \\
\text { autonomia estatutária, científica, pedagógica, } \\
\text { administrativa e financeira, sem prejuízo de } \\
\text { adequada avaliação da qualidade do ensino. }\end{array}$ \\
\hline
\end{tabular}

FONTE: QUADRO ELABORADO PELOS AUTORES (2019).

Notemos que ambas as constituições colocam a educação como um direito de todos e garantem a igualdade de acesso a mesma. Ademais, tanto na constituição brasileira quanto na portuguesa, o Ensino Básico é obrigatório e o Estado tem a obrigação de oferecê-lo gratuitamente.

Quanto as universidades brasileiras, estas possuem autonomia assegurada pela constituição, desde que não separem ensino, pesquisa e extensão, e as portuguesas, desde que a autonomia conferida não comprometa a qualidade do ensino.

\section{INSTITUIÇÕES FORMADORAS NO BRASIL E EM PORTUGAL}

Os programas de mobilidade que abordaremos abrangerão diversas universidades brasileiras e portuguesas, no entanto, o recorte de nossa pesquisa se dará a Universidade Federal de Uberlândia (UFU) e a Universidade de Coimbra (UC). A escolha destas universidades se deve ao fato de que estas foram as instituições que fizeram parte do processo de formação em Licenciatura em Matemática da autora desta pesquisa ${ }^{1}$.

O Quadro 4, a seguir, nos exibe pontos de convergência e divergência entre as duas instituições de ensino superior, UFU e UC, que nos propomos analisar. De acordo com a Comissão Europeia (2019), PORDATA (2019) e a UFU (2018) apresentados nos dados expostos, as duas instituições formadoras são instituições públicas de ensino. No entanto, os estudos na universidade pública brasileira são gratuitos e na universidade pública portuguesa é condicionado ao pagamento de propinas.

\footnotetext{
${ }^{1}$ Este artigo é um recorte da pesquisa desenvolvida no Trabalho de Conclusão de Curso (TCC). A autora foi bolsista do Programa de Licenciatura Internacional (PLI) em parceria com a Universidade de Coimbra (UC) no período de mobilidade 2017/2018.
} 
QUADRO 4 - INSTITUIÇÕES FORMADORAS: UFUE UC

\begin{tabular}{|c|c|c|c|c|c|}
\hline \multicolumn{2}{|c|}{ UFU } & & UC \\
\hline Fundação & Instituição & Ensino & Fundação & Instituição & Ensino \\
\hline $\begin{array}{c}\text { Fundada em } \\
1969\end{array}$ & Pública & Gratuito & Fundada em 1290 & Pública & $\begin{array}{c}\text { Parcialmente } \\
\text { subsidiado } \\
\text { pelo Estado } \\
\text { Pederalizada em } \\
1978\end{array}$
\end{tabular}

FONTE: QUADRO ELABORADO PELOS AUTORES (2019).

Por oferecer ensino gratuito, as despesas da Universidade Federal de Uberlândia são cobertas pelo Governo Federal. Em compensação, na Universidade de Coimbra, apesar dos estudos não serem gratuitos, os estudantes portugueses que estudam em Portugal pagam matrícula bem menores que os estudantes fora destas condições, uma vez que, o Estado Português subsidia parte dos estudos de portugueses ou equiparados.

No que diz respeito à fundação das instituições, percebemos que a Universidade de Coimbra tem 729 anos e é uma das universidades mais antigas do mundo, enquanto, a Universidade Federal de Uberlândia foi federalizada há 41 anos, o que representa uma diferença de 688 anos entre as duas universidades.

A seguir comparamos os cursos de Licenciatura em Matemática, oferecidos na UFU, pela Faculdade de Matemática (FAMAT) e pelo Instituto de Ciências Exatas e Naturais do Pontal (ICENP) e, na UC, pelo Departamento de Matemática (DM).

Podemos observar no Quadro 4 que o curso de matemática mais antigo, dentre os analisados, é o do Departamento de Matemática da UC, que surgiu antes mesmo do departamento integrar a atual Faculdade de Ciências e Tecnologia (FCT) da universidade. Enquanto o primeiro curso de matemática da UC surgiu no século XVIII, a FAMAT da UFU foi criada no século XX e o ICENP no século XXI.

QUADRO 5 - CURSOS DE LICENCIATURA EM MATEMÁTICA

\begin{tabular}{|c|c|c|c|}
\hline & \multicolumn{2}{|c|}{ UFU } & UC \\
\hline Faculdades & FAMAT & ICENP & DM (integrado à FCT) \\
\hline $\begin{array}{c}\text { Ano de criação das } \\
\text { faculdades }\end{array}$ & 1972 & 2007 & 1772 \\
\hline Duração prevista & 4 anos & 4 anos e meio & 3 anos \\
\hline Carga Horária / ECTS & 3320 horas & 2885 horas & $\begin{array}{l}4500 \text { a } 5400 \text { horas } \\
\text { (180 ECTS) }\end{array}$ \\
\hline No de Disciplinas & 40 & 42 & 28 \\
\hline $\begin{array}{c}\text { Aproveitamento mínimo } \\
\text { para aprovação }\end{array}$ & $60 \%$ & $60 \%$ & $50 \%$ \\
\hline Titulação / Habilitação & $\begin{array}{l}\text { Licenciado(a) em } \\
\text { Matemática; } \\
\text { Habilitado para dar } \\
\text { aulas }\end{array}$ & $\begin{array}{l}\text { Licenciado(a) em } \\
\text { Matemática; } \\
\text { Habilitado para dar } \\
\text { aulas }\end{array}$ & $\begin{array}{l}\text { Licenciado(a) em Matemática; } \\
\text { Habilitação para lecionar } \\
\text { condicionada à obtenção do } \\
\text { título de Mestre em Ensino da } \\
\text { Matemática, sendo } 2 \text { anos a } \\
\text { duração do mestrado }\end{array}$ \\
\hline
\end{tabular}

FONTE: QUADRO ELABORADO PELOS AUTORES (2019).

A duração prevista da Licenciatura em Matemática, a carga horária do curso e a quantidade de disciplinas na FAMAT, no ICENP e no DM são pontos divergentes. Além disso, o desempenho mínimo para aprovação nas disciplinas da universidade brasileira é $10 \%$ acima do exigido na universidade portuguesa em questão.

A Licenciatura em Matemática de menor duração é a oferecida pelo DM da UC, que possui uma diferença de um ano com a Licenciatura da FAMAT/UFU e de um ano e meio com a do ICENP/UFU. 
Em contrapartida, a carga horária, em horas, do curso do DM é muito superior à carga horária dos cursos de graduação em matemática ofertados pela FAMAT e pelo ICENP da UFU, mas esta diferença se dá pelo fato de ser incluído na carga da UC, o tempo destinado ao trabalho autônomo do estudante, o que não é contabilizado na carga horária da UFU.

A habilitação que o título de licenciado concede ao discente, ao concluir o curso, é divergente. O discente da FAMAT e do ICENP pode, ao término do curso, exercer o cargo de professor de matemática, enquanto o estudante graduado pelo DM da UC não pode, ao concluir o curso, atuar com professor. Para isso, o mesmo deve ingressar e concluir o mestrado em ensino da matemática.

Para finalizar a comparação dos cursos de Licenciatura em Matemática, abordaremos, a seguir, no Quadro 6, informações sobre as disciplinas de cunho pedagógico/educacional ofertadas pelos cursos.

QUADRO 6 - DISCIPLINAS DE CUNHO PEDAGÓGICO/EDUCACIONAL

\begin{tabular}{|c|c|c|c|}
\hline & \multicolumn{2}{|c|}{ UFU } & \multirow{2}{*}{$\begin{array}{c}\text { UC } \\
\text { DM }\end{array}$} \\
\hline & FAMAT & ICENP & \\
\hline $\begin{array}{l}\text { Disciplinas } \\
\text { educacionais }\end{array}$ & $\begin{array}{l}\text { Política e Gestão da Educação, } \\
\text { Psicologia da Educação, Estágio } \\
\text { Supervisionado 1, Estágio } \\
\text { Supervisionado 2; Estágio } \\
\text { Supervisionado 3, Estágio } \\
\text { Supervisionado 4, Ensino de } \\
\text { Matemática Através de Problemas, } \\
\text { Didática Geral, Metodologia do } \\
\text { Ensino da Matemática, Oficina de } \\
\text { Prática Pedagógica, Seminário de } \\
\text { Prática Educativa, }\end{array}$ & $\begin{array}{l}\text { Educação Matemática 1, Educação } \\
\text { Matemática 2, Educação Matemática } \\
\text { 3, Educação Matemática 4, } \\
\text { Projeto Integrado de Prática } \\
\text { Educacional 1, Projeto Integrado } \\
\text { de Prática Educacional 2, Projeto } \\
\text { Integrado de Prática Educacional } \\
\text { 3, Projeto Integrado de Prática } \\
\text { Educacional 4, Política e Gestão } \\
\text { da Educação, Psicologia da } \\
\text { Educação, Estágio Supervisionado } \\
\text { 1, Estágio Supervisionado 2, } \\
\text { Estágio Supervisionado 3, Estágio } \\
\text { Supervisionado 4, Didática Geral. }\end{array}$ & - \\
\hline $\begin{array}{c}\text { Carga Horária } \\
\text { Total }\end{array}$ & $860 \mathrm{~h}$ & $945 \mathrm{~h}$ & $0 \mathrm{~h}$ \\
\hline $\begin{array}{l}\text { Percentual em } \\
\text { relação ao curso }\end{array}$ & $26,71 \%$ & $32,76 \%$ & $0 \%$ \\
\hline
\end{tabular}

FONTE: QUADRO ELABORADO PELOS AUTORES (2019).

Ao analisarmos o Quadro 6, conseguimos compreender por que o discente graduado pelo curso de Licenciatura do Departamento de Matemática da Universidade de Coimbra não exerce, de imediato, a função de professor.

Notemos que, não há, no curso de Licenciatura do DM, disciplinas de cunho pedagógico/educacional que preparem e permitam o discente ter experiências em sala de aula. Enquanto nos cursos da FAMAT e do ICENP há uma carga horária, para disciplinas com este caráter, que corresponde, respectivamente, a $26,71 \%$ e $32,76 \%$ da carga horária total do curso.

Em contrapartida, como apresentado no quadro 5, a duração do curso oferecido pelo DM equivale a três quartos da Licenciatura da FAMAT e a dois terços da Licenciatura do ICENP. Portanto, ainda que seja exigido o Mestrado em Ensino da Matemática para que o discente da UC possa dar aulas, o tempo de formação para que este possa atuar como professor não se difere muito do tempo de formação dos cursos de Licenciatura em Matemática da UFU, visto que a duração do Mestrado em Ensino da Matemática é de dois anos.

Este quadro apresentado de disciplinas de cunho pedagógico/educacional nos remete a reflexão de Tardif (2002) que define o professor ideal é aquele que deve conhecer sua matéria, sua disciplina e seu programa, além de possuir certos conhecimentos relativos à ciências da educação e à pedagogia.

Assim sendo, como base nos quadros 5 e 6, inferimos que o discente do curso da Faculdade de Matemática/UFU consegue se habilitar para dar aulas em quatro anos, já o discente do Instituto de Ciências 
Exatas e Naturais do Pontal/UFU se habilita em quatro anos e meio e, o estudante do Departamento de Matemática/UC em cinco anos.

Destacamos que, apesar dos diferentes cenários de formação inicial do professor aqui mencionados, segundo Marim e Manso (2018) o desenvolvimento das múltiplas competências são essenciais para a formação do professor na contemporaneidade, visando uma melhor qualidade de educação nos países.

\section{PROGRAMAS DE MOBILIDADE INTERNACIONAL}

Nesta continuidade, abordaremos questões relacionadas aos programas de mobilidade, que nos permitirá identificar pontos de convergência e divergência entre os três programas de mobilidade internacional que nos propusemos e, isto, nos permitirá aferir a contribuição destes para a formação inicial de futuros professores.

Os três programas são fomentados por órgãos com características distintas. O Programa de Licenciatura Internacional (PLI) é fomentado pela Coordenação de Aperfeiçoamento de Pessoal de Nível Superior (CAPES), uma fundação governamental, já o Programa Ibero-Americanas é sustentado por uma instituição bancária privada, o Banco Santander, e o Programa Erasmus é provido pela Comissão Europeia, órgão executivo do bloco econômico designado União Europeia.

QUADRO 7 - PROGRAMAS DE MOBILLDADE DE INCENTIVO À FORMACÃO DOCENTE

\begin{tabular}{|c|c|c|c|}
\hline & PLI & Ibero-Americanas & Erasmus \\
\hline Órgão Fomentador & CAPES & Banco Santander & Comissão Europeia \\
\hline Ano de Implementação & 2010 & 2011 & 1984 \\
\hline $\begin{array}{l}\text { Duração da } \\
\text { mobilidade }\end{array}$ & $\begin{array}{c}1 \text { ano letivo (edital } n^{\circ} \\
74 / 2014)\end{array}$ & Até 6 meses & De três a doze meses \\
\hline Áreas de Estudos & Licenciaturas & Qualquer área de estudos & Qualquer área de estudos \\
\hline Países de Destino & Portugal e França & $\begin{array}{l}\text { Argentina, Brasil, } \\
\text { Colômbia, Chile, } \\
\text { Espanha, Peru, } \\
\text { Porto Rico, Portugal, } \\
\text { México ou Uruguai }\end{array}$ & $\begin{array}{c}28 \text { estados membros da UE } \\
+ \\
\text { Antiga República Jugoslava } \\
\text { da Macedônia, Islândia, } \\
\text { Listenstaine, Noruega, Sérvia } \\
\text { e } \\
\text { Turquia }\end{array}$ \\
\hline $\begin{array}{c}\text { Potencial de } \\
\text { equivalência de } \\
\text { disciplinas } \\
\end{array}$ & $\begin{array}{c}\text { Sim } \\
\text { (de acordo com o plano de } \\
\text { estudos) }\end{array}$ & $\begin{array}{c}\text { Sim } \\
\text { (de acordo com o plano } \\
\text { de estudos) }\end{array}$ & $\begin{array}{c}\text { Sim } \\
\text { (de acordo com o plano de } \\
\text { estudos) }\end{array}$ \\
\hline Regime de estudos & Dedicação exclusiva & Dedicação exclusiva & $\begin{array}{c}\text { Dedicação exclusiva ou } \\
\text { parcial }\end{array}$ \\
\hline $\begin{array}{l}\text { Acompanhamento } \\
\text { docente presencial }\end{array}$ & $\begin{array}{l}\text { Missão de Trabalho dos } \\
\text { coordenadores brasileiros }\end{array}$ & Não & Não \\
\hline $\begin{array}{l}\text { Propinas pagas à } \\
\text { universidade de } \\
\text { acolhimento }\end{array}$ & $\begin{array}{l}\text { Pagas pelo Órgão } \\
\text { Fomentador }\end{array}$ & $\begin{array}{c}\text { Isento } \\
\text { (desde que haja } \\
\text { um acordo entre as } \\
\text { universidades) }\end{array}$ & Isento \\
\hline Benefícios/Recursos & $\begin{array}{c}\text { Mensalidades de } 870 € \\
\text { Auxílio Deslocamento: } \\
\text { Duas parcelas de } 1255 € \\
\text { Auxílio Instalação: } 1300 € \\
\text { Auxílio Seguro Saúde: } \\
1080 €\end{array}$ & $\begin{array}{c}3.000 \text { € pra custear } \\
\text { todas as despesas com a } \\
\text { mobilidade }\end{array}$ & $\begin{array}{l}\text { Mensalidades de } 340 € \text { (sendo } \\
\text { Portugal o país de destino) } \\
\text { Auxílio deslocamento (de } \\
\text { acordo com a distância entre } \\
\text { os países) } \\
\text { Bolsas Suplementares (para } \\
\text { estudantes com necessidades } \\
\text { especiais ou com dificuldades } \\
\text { socioeconômicas) }\end{array}$ \\
\hline
\end{tabular}




\begin{tabular}{|c|c|c|c|}
\hline & PLI & Ibero-Americanas & Erasmus \\
\hline Produto Final & $\begin{array}{c}\text { certificado de estudos } \\
\text { e relatório final }\end{array}$ & certificado de estudos & $\begin{array}{c}\text { certificado de estudos } \\
\text { e relatório final }\end{array}$ \\
\hline $\begin{array}{c}\text { Objetivo Geral dos } \\
\text { programas }\end{array}$ & $\begin{array}{c}\text { Melhoria da qualificação } \\
\text { profissional } \\
\text { na formação inicial de } \\
\text { professores }\end{array}$ & \begin{tabular}{|c|} 
Propiciar o acesso a \\
culturas estrangeiras \\
realizando cursos em \\
renomadas universidades \\
Ibero-Americanas \\
\end{tabular} & $\begin{array}{l}\text { Promover o intercâmbio de } \\
\text { estudantes do ensino superior } \\
\text { da UE e apoiar atividades } \\
\text { voltadas ao ensino superior }\end{array}$ \\
\hline
\end{tabular}

FONTE: QUADRO ELABORADO PELOS AUTORES (2019).

Quanto à implementação dos programas, podemos verificar que o Erasmus é o programa que promove intercâmbio estudantil há mais tempo, completando, neste ano, 35 anos de história. O PLI e o Programa Ibero-Americanas foram criados em datas bem próximas e estão colaborando com a formação da comunidade acadêmica, respectivamente, há nove e oito anos.

Em relação à duração dos programas de formação, também encontramos divergências. O PLI subsidiado pela CAPES possui, atualmente, duração de um ano letivo de estudos na instituição de acolhimento. Enquanto a mobilidade promovida pelo Banco Santander e pela Comissão Europeia é variável e não supera o período de mobilidade do PLI.

Sobre as áreas de estudos, o PLI é o programa mais restrito, pois restringe a participação exclusivamente às licenciaturas; no entanto, essa limitação poderá ser melhor compreendida quando compararmos os objetivos dos três programas. Já os Programa Ibero-Americanas e Erasmus convergem neste quesito, pois ambos não possuem restrições quanto à área de estudos dos candidatos.

Quanto aos países de destino, percebemos que o Programa Erasmus é o mais abrangente, tendo 34 opções de destino; em seguida, vem o Programa Ibero-Americanas, com dez alternativas, e, por último, o PLI, com duas opções. No entanto, os três programas convergem com relação a um único destino comum, os três oferecem Portugal como opção de mobilidade estudantil.

A única convergência total para os programas analisados é referente ao tópico potencial de equivalência de disciplinas. Em todos os programas, as disciplinas do plano de estudos que se assemelham na grade curricular da instituição de origem e de acolhimento têm potencial de equivalência e são validadas no currículo da Instituição de Ensino Superior (IES) de origem quando o estudante conquistar aprovação na IES de acolhimento.

Relativamente ao regime de estudos, tanto o PLI quanto o Programa Ibero-Americanas exigem dedicação exclusiva, isto é, durante o período de estudos internacional o discente deve dedicar-se exclusivamente as atividades de estudo, sendo proibido exercer qualquer outra atividade. Em contrapartida, o Programa Erasmus não impõe esta condição, sendo opção do estudante exercer, ou não, outra atividade, no entanto, a extra atividade do discente não pode comprometer o seu desempenho na instituição de ensino.

Quanto ao acompanhamento presencial, além de existir um coordenador do PLI na instituição de acolhimento, os estudantes PLI possuem acompanhamento presencial dos coordenadores brasileiros, sendo este acompanhamento custeado duas vezes ao ano, através da chamada missão de trabalho. Por meio desta missão, o estudante PLI recebe o apoio presencial do coordenador brasileiro na fase inicial e na metade de seu intercâmbio. Já os outros programas não possuem este acompanhamento presencial dos coordenadores da IES de origem.

A mobilidade internacional, por meio do PLI, é condicionada ao pagamento de propinas na instituição de acolhimento; assim sendo, o órgão fomentador do programa precisa custear as propinas na IES de acolhimento. Já o estudante Erasmus é isento destas propinas e o bolsista do Programa Ibero-Americanas também é isento do pagamento de propinas, desde que a sua IES de origem tenha um acordo com a IES de destino e ambas sejam conveniadas ao Santander Universidades.

Com relação aos recursos financeiros concedidos aos estudantes em mobilidade, percebemos que o PLI é o único programa que custeia integralmente as despesas que o discente possa ter com o intercâmbio. Enquanto no PLI Portugal o estudante recebe 15330 euros, distribuídos ao longo de toda a mobilidade, no Programa Ibero Americanas é fornecido ao estudante um único pagamento no valor de 3 mil euros, 
sendo este valor um auxílio para todos os custos da mobilidade cuja duração é de até seis meses. Quanto ao Programa Erasmus, este oferece um auxílio financeiro para o deslocamento do país de origem ao país de mobilidade, que varia de acordo com a distância entre os países e a mensalidade recebida durante a mobilidade constitui um apoio financeiro e não cobre todas as despesas mensais do estudante.

Assim sendo, inferirmos que dentre os programas analisados, o PLI é o único que concede ao estudante um suporte financeiro que cobre todos os custos derivados do intercâmbio. Já os demais programas fornecem apenas um auxílio financeiro aos estudantes.

Sobre o produto final do intercâmbio, além do certificado de estudo, constando as disciplinas cursadas durante a mobilidade, exigido nos três programas, o PLI e o Programa Erasmus exigem do estudante um relatório final referente ao período de mobilidade. Já no regulamento do Programa Ibero-Americanas, não é identificada a exigência deste relatório.

A última observação em relação ao Quadro 7 está relacionada ao objetivo geral dos programas. Comparando os objetivos, percebemos que o propósito do PLI é contribuir para a melhoria da formação inicial docente; por essa razão, as áreas de estudos abrangidas pelo programa são compostas apenas por licenciaturas, apesar destas também serem restritas. Por outro lado, o foco do Programa Ibero-Americanas é ganho cultural, proveniente do contato com diferentes ambientes culturais e o intuito do Programa Erasmus é promover o intercâmbio de estudantes e apoiar atividades que contribuam com a qualidade do ensino superior europeu.

No entanto, ainda que os programas Ibero-Americanas e Erasmus não tenham como fim a melhoria da formação docente, indiretamente eles contribuem para tal, uma vez que não há restrição quanto à área de estudos e, logo, o futuro professor pode participar dos programas e, assim, ter acesso a cursos de formação inicial com contribuições diferentes das promovida por sua IES de origem e que complementem sua formação.

Os programas de mobilidade internacional pode propiciar aos estudantes a reflexão crítica sobre a prática essencial na sua própria formação docente, como nos lembra Freire (2002), da importância da socialização das experiências desses futuros profissionais, por meio do intercâmbio com diversos estudantes oriundos de vários países, propiciando a partilha de saberes, pesquisas, atividades, estudos, entre outros.

A seguir, apresentaremos a comparação dos requisitos a serem cumpridos para que o discente possa se candidatar aos programas de mobilidade PLI, Ibero-Americanas e Erasmus, conforme os dados expostos no Quadro 8. Observamos que os três programas possuem requisitos convergentes e divergentes.

\section{QUADRO 8 - REQUISITOS PARA CANDIDATURA AOS PROGRAMAS}

\section{Requisitos}

(a) ser brasileiro ou estrangeiro com visto de residência permanente no Brasil;

(b) estar em dia com as obrigações eleitorais;

(c) ter obtido nota no ENEM nota igual ou superior a 600 pontos;

(d) ter cursado todo o ensino médio em escolas públicas brasileiras ou em escolas PLI particulares na condição de bolsista integral, durante todo o período de estudos na rede privada, em função de baixa renda familiar;

(e) ter integralizado no mínimo 20\% e no máximo 80\% dos créditos obrigatórios do curso; (f) ser selecionado pelo coordenador brasileiro e aceito pela universidade portuguesa;

(g) estar apto a iniciar as atividades relativas ao projeto imediatamente após ser aprovado.

(a) ser pessoa física habilitada a todos os atos da vida civil, sendo ainda residente e domiciliado em território nacional e maior de 18 anos;

(b) ser selecionado pela IES conveniada ao SANTANDER e deverá, em todo caso, cumprir os critérios de elegibilidade, condições e procedimentos estabelecidos pela mencionada IES

SANTANDER no correspondente processo de seleção, sem qualquer interferência do SANTANDER;

(c) estar regularmente matriculado na IES conveniada ao SANTANDER, durante todo o processo de seleção e, obrigatoriamente, durante todo o período de participação e realização do Programa, apresentando excelente e comprovado desempenho acadêmico, baixa condição econômica e social e conta corrente ativa no SANTANDER; 


\begin{tabular}{|c|c|}
\hline & Requisitos \\
\hline SANTANDER & $\begin{array}{c}\text { (d) assinar, obrigatoriamente, o competente “Termo de adesão” e concordância às } \\
\text { disposições constantes do documento “Princípios Gerais dos Programas de Bolsas do } \\
\text { Santander Universidades”, declarando que preenche todos os requisitos específicos } \\
\text { estabelecidos. }\end{array}$ \\
\hline \multirow{6}{*}{ Erasmus } & $\begin{array}{c}\text { (a) atingir determinado nível de conhecimento da língua principal de ensino até ao início do } \\
\text { período de estudo; }\end{array}$ \\
\hline & $\begin{array}{l}\text { Sendo as IES responsáveis pela seleção e distribuição de bolsas, este processo deve ocorrer } \\
\text { de maneira justa e transparente, tornando público os critérios de elegibilidade utilizados, } \\
\text { que podem ser, por exemplo: }\end{array}$ \\
\hline & (b) desempenho acadêmico do candidato; \\
\hline & (c) experiências anteriores de mobilidade; \\
\hline & (d) motivação; \\
\hline & (e) experiência anterior no país de acolhimento. \\
\hline
\end{tabular}

FONTE: QUADRO ELABORADO PELOS AUTORES (2019).

Cada programa possui critérios de elegibilidade específicos, como apresentamos no quadro acima. Assim sendo, destacaremos requisitos convergentes dos três programas de formação.

Notemos que em todos os programas é avaliado o desempenho do estudante; no PLI, por exemplo, é exigida a nota mínima de 600 pontos no Exame Nacional do Ensino Médio (ENEM). Já no Programa Ibero-Americanas, é necessário que o estudante comprove um bom desempenho acadêmico; e no Programa Erasmus, é sugerido aos responsáveis pela seleção de candidatos que levem em consideração o desempenho acadêmico dos estudantes.

Ademais, em todos os programas, além de atenderem aos requisitos preestabelecidos nos regulamentos de cada programa, os estudantes precisam cumprir os critérios de elegibilidade definidos pelos responsáveis, na IES de origem, pela seleção de candidatos.

O Programa de Licenciaturas Internacionais e o Programa Ibero-Americanas priorizam estudantes que possuem condições financeiras mais vulneráveis, o que contribuiu para diminuir as desigualdades de acesso à educação devido à baixa condição econômica e social. Mas, como vimos no tópico Benefícios/ Recursos do Quadro 7, no Programa Erasmus, o candidato com dificuldades socioeconômicas pode concorrer a bolsas suplementares que o ajudarão durante o intercâmbio, ou seja, apesar do programa não priorizar estudantes desfavorecidos economicamente, existe a possibilidade de estes obterem bolsas suplementares que assegurem a qualidade financeira da mobilidade do estudante.

\section{CONSIDERAÇÕES FINAIS}

A análise do contexto sociopolítico dos países, Brasil e Portugal nos ajuda a identificar divergências no grau de complexidade administrativa dos dois países, visto que a extensão territorial portuguesa é, cerca de noventa e duas vezes menor que a brasileira e a população de Portugal representa, aproximadamente, um vinte avos da população brasileira, o que torna a administração do Brasil mais desafiadora.

Além disso, percebemos a forte relação entre os países-membros do bloco econômico União Europeia, do qual Portugal faz parte, pois, além de colaborarem em vários aspectos educacionais, facilitando e incentivando, por exemplo, a mobilidade estudantil nos países-membros do bloco, a maioria dos integrantes, incluindo Portugal, facilita as atividades comerciais, adotando o euro como moeda oficial comum.

Outro fator de discussão e reflexão se refere à estrutura da formação inicial dos futuros docentes nas instituições UFU e UC. A primeira observação é que na UFU o tempo das graduações é determinado por horas presenciais e na UC pelo Sistema Europeu de Transferência e Acumulação de Créditos (ECTS), que inclui tanto a parte presencial como o trabalho autônomo dos estudantes. 
Desta forma, ao analisarmos a carga horária dos cursos da UFU e da UC, percebemos que essa é muito superior no Departamento de Matemática da UC; no entanto, ressaltamos que maior carga horária não necessariamente significa melhor performance ou maior aprendizado.

Outra diferença é com relação à estrutura curricular dos cursos de graduação nas duas instituições de ensino. Percebemos que a graduação em matemática da FAMAT/UFU e do ICENP/UFU, além da teoria matemática, contempla a parte educacional/pedagógica, permitindo o futuro professor vivenciar práticas docentes desde sua formação inicial, enquanto que o discente do DM/UC só terá essa oportunidade ao ingressar no Mestrado em Ensino da Matemática, sendo este mestrado uma condição necessária para atuar como docente na educação básica portuguesa.

No entanto, ainda que, os discentes do Departamento de Matemática da UC precisem do Mestrado em Ensino da Matemática para se habilitarem a docência, constatamos que o período de estudos e preparação destes não é muito superior ao dos discentes da Faculdade de Matemática e do Instituto de Ciências Exatas e Naturais do Pontal da UFU.

Finalmente, começaremos a abordar os programas de mobilidade internacional descritos na pesquisa falando, primeiramente, sobre o período de cada mobilidade.

A duração da mobilidade dos programas é um aspecto divergente entre eles, haja vista que enquanto a mobilidade dos Programas Ibero-Americanas e Erasmus tem duração variável, sendo o primeiro de até seis meses e o segundo, em geral, de três a doze meses, a mobilidade do PLI, atualmente, é de exatamente dois semestres letivos.

Com relação ao apoio financeiro ofertado aos estudantes, percebemos que o PLI é o único programa que tem a preocupação de fornecer todo o suporte para que os estudantes não precisem se preocupar com suas despesas durante a mobilidade e se dediquem, exclusivamente, aos estudos na IES de acolhimento.

O PLI é o único cujo fim é a melhoria da qualificação profissional na formação inicial de professores. No entanto, apesar dos outros programas terem focos diferentes, acreditamos que eles contribuem indiretamente com a formação inicial de docentes, uma vez que não há restrições quanto à área de estudos dos candidatos dos programas, o que possibilita futuros professores terem acesso, por meio destes, a renomadas IES do mundo e, consequentemente, ampliarem suas perspectivas sobre o ensino.

Outra importante diferença encontrada é com relação ao regime de estudos dos programas. O PLI e o Programa Ibero-Americanas exigem dedicação exclusiva às atividades da IES de acolhimento, enquanto o Programa Erasmus permite que os estudantes conciliem as atividades da IES com outra, desde que o desempenho na universidade não seja comprometido. Essa possibilidade de dedicação parcial aos estudos Erasmus pode ser positiva, pois oportuniza a diversidade de experiências, desde que o estudante tenha o devido acompanhamento dos coordenadores para conciliar as diferentes atividades.

Um diferencial do estudante PLI é com relação ao acompanhamento docente que lhe é oferecido. Além do acompanhamento de um coordenador PLI na IES de acolhimento, o estudante PLI possui o acompanhamento de um dos coordenadores PLI da universidade de origem por um período de sete a vinte dias, duas vezes, durante sua mobilidade. Esse acompanhamento é devido à chamada missão de trabalho financiada pela CAPES, cujo fim é acompanhar presencialmente e orientar os discentes com questões pertinentes, tais como resolução de problemas educacionais junto à instituição de acolhimento e orientações de estudos, ao passo que os participantes dos outros dois programas não têm esse acompanhamento presencial dos coordenadores da IES de origem.

Para complementar, ressaltamos que apesar da atual constituição portuguesa exprimir a preocupação com o progressivo estabelecimento da educação gratuita, em todos os graus de ensino, esta ainda não é uma realidade no país.

Assim sendo, apesar de existirem as instituições públicas de ensino superior em Portugal, o ensino nessas é, ainda, condicionado ao pagamento de propinas, ao passo que, as instituições públicas brasileiras são totalmente gratuitas, o que acreditamos facilitar o acesso de estudantes ao Ensino Superior.

No entanto, o ingresso no Ensino Superior não nos assegura a formação de docentes que desenvolverão um trabalho de qualidade. Pois, como coloca Ghedin (2009), o processo formativo é o que torna o professor um profissional do ensino de qualidade, ou seja, é a formação do indivíduo que condiciona o desenvolvimento das competências necessárias para o bom desempenho docente. 
Como defendido por Tardif (2002), as formações inicial e continuada fazem parte dos saberes docentes e quanto mais experiências, em contextos educacionais diferentes, mais valor é agregado ao futuro professor. Desta forma, nos certificamos que quanto mais completa e abrangente for a formação do futuro docente, melhor será seu desempenho profissional e, é a partir daí, que salientamos a importância dos programas de incentivo à formação docente, tais como os programas de mobilidade internacional analisados.

A experiência da mobilidade internacional proporciona aos futuros docentes o contato com estudantes e professores de diversas universidades e isto favorece a aquisição de competências profissionais e possibilita a ampliação de estratégias no processo ensino e aprendizagem. A troca dos saberes na formação docente, segundo Tardif (2002) é fundamental, pois os programas em questão proporcionam aos estudantes em mobilidade momentos únicos na construção inicial de sua profissão.

Esse contato com estudantes de outras universidades cuja forma de ensino se distingue, em alguns aspectos, da IES a qual pertencemos, nos possibilita diversas troca de experiências, as quais expandem nosso conhecimento e, consequentemente, ampliam nossa visão sobre o ensino. Desta forma, nos certificamos que o contato com diferentes culturas de ensino pode ter um grande diferencial na formação inicial e continuada dos professores e, por isso, o investimento governamental para que o estudante tenha acesso a diferentes formas de ensino é tão importante.

No entanto, reconhecemos que somente por meio da ação conjunta entre governantes e educadores formaremos docentes competentes e hábeis que garantam a qualidade do ensino, pois, da mesma forma que o professor não é o único responsável pelo bom ou mau desempenho dos alunos, o Estado não é o único responsável pela boa formação docente.

Por fim, acreditamos que a comparação e as exposições realizadas nesta pesquisa permitirão que cidadãos e governantes percebam a importância do apoio às políticas públicas educacionais e do reconhecimento docente, para que assim, haja um aumento progressivo da qualidade educacional.

Para que possamos continuar a discussão dessa temática, partindo da importância dos programas de mobilidades internacionais realizadas por brasileiros em Portugal, principalmente no que se refere ao PLI, durante o período de graduação, apontamos a possibilidade de investigar as contribuições especificamente desse programa, em relação ao desenvolvimento profissional e acadêmico (pós-graduação) de cada egresso que participou em sua formação inicial.

\section{REFERÊNCIAS}

BELCHIOR, A. M. As Constituições Republicanas Portuguesas: Direitos fundamentais e representação política (1911-2011). 2013. Disponível em: http://www.mundossociais.com/temps/ livros/02_14_14_05_constituicoesrepublicanasfftindiceprolintrod.pdf >. Acesso em: 14 mar. 2020.

BEREDAY, G. El método comparativo en pedagogía. Barcelona: Herder, 1968.

BRASIL. Base Nacional Comum Curricular - Educação é a Base. 2018. Disponível em: http:// basenacionalcomum.mec.gov.br/. Acesso em: 05. Mai.2020.

BRASIL. Ministério da Educação e Cultura (MEC). Referências para Formação de Professores. 1999. Disponível em: https://www.novaconcursos.com.br/blog/pdf/referencias-formacao-professores. pdf. Acesso em: 19 fev. 2020.

BRASIL. Ministério da Educação e Cultura. Graduação: Universidade Federal de Uberlândia. Disponível em: http://emec.mec.gov.br/emec/consulta-cadastro/detalhes-ies/d96957f455f6405d14c654 2552b0f6eb/Mtc=. Acesso em: 11 fev. 2020.

CABALLERO, A; MANSO, J; MATARRANZ, M; VALLE, J. M. Investigación em Educación Comparada: pistas para investigadores noveles. Revista Latinoamericana de Educación Comparada - Estudios e Investigaciones. Caba/AR, n. 9, p. 39-56, jan./jul. 2016. 
CARDOSO, M. C.; HORA, D. M. (2013). Competências e Habilidades: alguns desafios para a formação de professores. Disponível em: http://www.histedbr.fe.unicamp.br/acer_histedbr/jornada/ jornada11/artigos/7/artigo_simposio_7_713_micheli_ccardoso@yahoo.com.br.pdf. Acesso em: 22 mar. 2020.

COMISSÃO EUROPEIA. Erasmus+ Guia do Programa. 2019. Disponível em: https://ec.europa.eu/ programmes/erasmus-plus/resources/documents/erasmusprogramme-guide-2019_pt. Acesso em: 11 mar. 2020.

FREIRE, P. Pedagogia da autonomia: Saberes Necessários à Prática Educativa. Rio de Janeiro: Paz e Terra, 2002.

GHEDIN, E. Tendências e dimensões da formação do professor na contemporaneidade. 2009. Disponível em: https://construindoumaprendizado.files.wordpress.com/2012/08/tendenciasdafrmacprof.pdf. Acesso em: 05.mai.2020.

INSTITUTO BRASILEIRO DE GEOGRAFIA E ESTATÍSTICA (IBGE). População brasileira. (2020). Disponível em: < https://cidades.ibge.gov.br/brasil/panorama>. Acesso em 24 mar. 2020.

INEP. Programa Internacional de Avaliação de Estudantes (Pisa). Disponível em: http://portal.inep. gov.br/pisa. Acesso em: 05.mai.2020.

MARIM, V.; MANSO, J. A formação inicial de professor da educação básica no Brasil e na Espanha. Salamanca: Fahren House, 2018.

NÓVOA, A. Formação de professores e trabalho pedagógico. Lisboa, Pt: Educa, 2002.

OCDE. Professores são importantes: atraindo, desenvolvendo e retendo professores eficazes. São Paulo: Coedição Moderna: OCDE, 2006.

RAVENTÓS, F. El fundamento de la metodología comparativa en educación. Revista Educar, Barcelona/ES, n. 3, p. 61-75, jan./jul. 1983.

TARDIF, M. Saberes docentes e formação profissional. Petrópolis: Vozes, 202.

UNIÃO EUROPEIA. Comissão Europeia. abr. 2019. Disponível em: https://europa.eu/europeanunion/about-eu/institutions-bodies/europeancommission_pt. Acesso em: 22 mar. 2020. 